\title{
ZASEUGI FILOLOGII KLASYCZNEJ KUL W PROPAGOWANIU LITERATURY WCZESNOCHRZEŚCIJAŃSKIEJ
}

Studium filologii klasycznej KUL rozpoczęło swą działalność od początku istnienia Uniwersytetu, tzn. od roku akademickiego 1918/1919 ${ }^{1}$. Jego pierwszym kierownikiem był do 1923 roku prof. nadzw. dr Stefan Srebrny, a po wyjeździe profesora do Wilna następcą w latach 1923-1946 został dr Mieczysław Popławski, dotychczasowy lektor języków starożytnych, który najpierw otrzymał stopień zastępcy profesora, w 1928 roku - tytuł profesora nadzwyczajnego, a po wojnie w 1944 roku - tytuł profesora zwyczajnego. Po jego śmierci (29 XII 1946) kierownikiem studium aż do roku 1953 został zastępca profesora dr Marian Plezia, od roku 1948 - docent, a od 1949 - profesor kontraktowy. Czwartym z kolei kierownikiem studium filologii klasycznej KUL w okresie 1953-1962 była dr (od 1954 r. docent) Leokadia Małunowiczówna, która w roku akademickim 1953/1954 została również kierownikiem II Katedry (łacińskiej) i seminarium łacińskiego; po jej śmierci (1 V 1980) od 14 IX 1981 r. kierownikiem II Katedry Filologii Klasycznej, przy której wykładano również literaturę wczesnochrześcijańską, został ks. doc. dr hab. Henryk Wójtowicz. Kolejnymi kierownikami Sekcji Filologii Klasycznej KUL byli: doc. (od 1967 r. prof. nadzw. Janina Niemirska-Pliszczyńska (1963-1969, 1972-1974), doc. (od 1972 r. prof. nadzw.) Leokadia Małunowiczówna (1969-1972, 1974-1980), doc. dr hab. (od 1985 r. prof. nadzw., od 1992 prof. zwycz.) Krystyna Stawecka (1980-1983, 1987-1990, 1991-1993), ks. doc. dr hab. (od r. 1992 prof. nadzw.) Henryk Wójtowicz (1983-1987, 1990-1991, 1993-1998), a obecnie od 1 X 1998 roku jest nim prof. dr hab. Robert Chodkowski.

W ramach reorganizacji Sekcji Filologii Klasycznej, na wniosek Rady Sekcji i przy poparciu Rady Wydziału Nauk Humanistycznych, Senat KUL uchwałą z dnia 28 maja 1994 roku przemianował II Katedrę Filologii Klasycznej na Katedrę Filologii Klasycznej Łacińskiej i powierzył jej kierownictwo ks. prof.

${ }^{1}$ Por. J. Niemirska-Pliszczyńska, Pięćdziesięciolecie filologii klasycznej na Katolickim Uniwersytecie Lubelskim, RH 16(1968) z. 3, 5-21. 
Henrykowi Wójtowiczowi, który prowadził ją do emerytury tzn. do 30 IX 1998 roku. Obecnym kierownikiem tej Katedry został dr hab. Andrzej Budzisz. Uchwałą z dnia 28 maja 1994 roku Senat powołał do istnienia m.in. Katedrę Literatury Wczesnochrześcijańskiej i powierzył jej kierownictwo ks. prof. dr hab. Augustynowi Eckmannowi. Sekcja posiada od roku 1980/1981 prawo nadawania wszystkich stopni naukowych. Pierwszym jej doktorem habilitowanym w zakresie nauk humanistycznych - literaturoznawstwo - filologia klasyczna, został Andrzej Budzisz. W drugim semestrze na roku IV jest uwzględniana w naszej Sekcji także wczesnochrześcijańska literatura grecka i łacińska w wymiarze 4 godzin tygodniowo ( 2 godz. literatury greckiej i 2 godz. literatury łacińskiej) z egzaminem po VIII semestrze studiów.

W okresie siedemdziesięciolecia studium filologii klasycznej KUL (19181988) na ogólną liczbę 254 prac magisterskich napisano 48 prac na temat piśmiennictwa wczesnochrześcijańskiego ${ }^{2}$. Dr Leokadia Małunowiczówna, która w roku akad. 1951/1952 została zatrudniona w Sekcji Filologii Klasycznej KUL na etacie adiunkta, po przybyciu z UMK w Toruniu, jako pierwsza od 1958 roku zaczęła proponować studentom tematy prac magisterskich $\mathrm{z}$ literatury wczesnochrześcijańskiej. Pod jej kierunkiem opracowano z tej dziedziny 24 tematy (w tym 9 translatorskich i 15 problemowych). Ich wykaz podałem we wspomnianym opracowaniu zamieszczonym w „Vox Patrum”3. Dwie ostatnie prace o charakterze translatorskim dokończono już po jej śmierci pod kierunkiem ks. doc. dra hab. Henryka Wójtowicza.

Po roku 1972 również na seminarium greckim pod kierunkiem prof. dr Janiny Niemirskiej-Pliszczyńskiej napisano 5 problemowych prac magisterskich na podstawie Stromateis Klemensa Aleksandryjskiego ${ }^{4}$. Także pod kierunkiem prof. dra hab. Henryka Podbielskiego powstały 2 prace thumaczeniowe pism Klemensa Aleksandryjskiego - 1 księga Pedagoga i Protreptikos 5 . Ponadto ks. doc. dr hab. Remigiusz Popowski kierowal dwiema problemowymi pracami: magisterską i doktorską ${ }^{6}$.

Prace magisterskie z literatury wczesnochrześcijańskiej powstawały w ostatnich latach siedemdziesięciolecia na seminariach: doc. dra Mariana Nagnajewicza (1) i doc. dra Michała Kaczmarkowskiego $(2)^{7}$ - translatorskie, oraz

${ }^{2}$ Pisałem o tym we wcześniejszym opracowaniu na temat Sekcji Filologii Klasycznej KUL w VoxP 9(1989) z. 16, s. 369-374.

3 Por. tamże, s. 369-370.

${ }^{4}$ Por. Klemens Aleksandryjski, Kobierce zapisków filozoficznych dotyczących prawdziwej wiedzy. Z języka greckiego przełożyła, wstępem, komentarzem i indeksami opatrzyła J. NiemirskaPliszczyńska, t. 1-2, Warszawa 1994, ss. 393+452. Tytuły prac magisterskich zob. VoxP 9(1989) z. 16, $370 \mathrm{n}$.

${ }^{5}$ Por. VoxP 9(1989) z. 16, 371

6 Tamże.

7 Tamże. 
pod kierunkiem ks. doc. dra hab. Henryka Wójtowicza $(10)^{8}, \mathrm{z}$ których 3 były problemowe, a pozostałe tłumaczeniowe.

Także wykłady monograficzne dla studentów filologii klasycznej, z III-V roku studiów przedstawiały często problematykę patrystyczną w aspekcie filologicznym. Prowadziła je najpierw prof. dr Leokadia Małunowiczówna koncentrując się na następujących zagadnieniach: Grecko-łacińska epistolografia wczesnochrześcijańska, Konsolacja w pismach autorów wczesnochrześcijańskich, Problem tradycji literackiej w piśmiennictwie starochrześcijańskim, Koncepcja rodziny wczesnochrześcijańskiej ${ }^{9}$. Ks. doc. dr hab. Henryk Wójtowicz omawiał zaś na swoich wykładach monograficznych następujące tematy: Teoria i praxis $w$ antyku chrześcijańskim: Klemens Aleksandryjski, Orygenes, Grzegorz z Nyssy i Grzegorz z Nazjanzu (w roku akad. 1980/1981), Myśl augustyńska o Bogu, człowieku i świecie (1982/1983), Doktryna Grzegorza z Nyssy (1983/1984), Teologiczna terminologia łacińska w okresie poklasycznym: m.in. nazewnictwo eucharystyczne u św. Augustyna (1988/1989). Podobnie ks. doc. dr hab. Augustyn Eckmann prowadził w tym czasie wykłady monograficzne zajmując się następującymi problemami: Stosunek św. Augustyna do kultury antycznej (1984/1985), Szanse i trudności monoteizmu w pierwszych wiekach po Chrystusie (1986/1987), "Deificatio hominis» w nauczaniuśw. Augustyna (1987/ 1988), Literackie i teologiczne zasady interpretacji Pisma św. (1988/1989), a ks.dr S. Longosz temat: Efez centrum kultury pogańskiej i chrześcijańskiej (1981/1982).

Na seminariach omawiano często, w zależności od potrzeb i zainteresowań ich uczestników, także teksty patrystyczne. Tak np. na seminarium łacińskim ks. doc. Wójtowicza w roku akad. 1984/1985 komentowano temat: Actio $i$ contemplatio $u$ św. Augustyna, biorąc za punkt wyjścia Confessiones. Ks. doc. Eckmann natomiast przedstawił na swoim seminarium lacińskim dla roku IV temat: Wpływ kultury klasycznej na duchowy rozwój św. Augustyna $(1989 / 1990)$.

Sekcja Filologii Klasycznej KUL współpracowała w latach 60-tych i następnych, najpierw z Sekcją Filologiczną, a w latach 70-tych i następnych, z Sekcją Patrystyczną przy Komisji Episkopatu ds. Nauki Katolickiej, biorąc czynny udział w ich corocznych i nadzwyczajnych spotkaniach, wygłaszając na nich odczyty, informując na bieżąco o swoich osiągnięciach i prowadzonej przez siebie działalności w zakresie propagowania literatury wczesnochrześcijańskiej.

Studentów IV roku obowiązuje od roku akad. 1985/1986 składanie kolokwium z lektury w oryginale Confessiones (IX 6-12) i De civitate Dei (I 15) św. Augustyna, wprowadzone przez Sekcję na wniosek ks. H. Wójtowicza.

${ }^{8}$ Tamże.

9 Por. Ks. S. Longosz, Profesor dr Leokadia Małunowiczówna niezmordowany propagator antyku chrześcijańskiego w Polsce, w: Chrześcijanie, red. B. Bejze, t. XIII, Warszawa 1984, s. 311. 
Studia nad antykiem chrześcijańskim na Sekcji Filologii Klasycznej KUL kontynuowano jeszcze intensywniej w latach 1989-1999. W tym dziesięcioleciu przygotowano z problematyki wczesnochrześcijańskiej aż 34 prace magisterskie i 4 dysertacje doktorskie oraz przeprowadzono jeden przewód habilitacyjny.

W Katedrze Filologii Klasycznej Łacińskiej pod kierunkiem ks. Henryka Wójtowicza (od 1981 docenta, a od 1992 prof. nadz.) 8 prac magisterskich o charakterze translatorskim ze wstępem i komentarzem. Przetłumaczono w nich wybrane pisma: św. Gelazjusza papieża (1), św. Ildefonsa z Toledo (1), św. Ambrożego (5) oraz 5 homilii ze zbioru Chrysostomus Latinus (1) ${ }^{10}$.

Najwięcej prac magisterskich w ostatnim dziesięcioleciu powstało w Katedrze Literatury Wczesnochrześcijańskiej pod kierunkiem ks. prof. Augustyna Eckmanna, a mianowicie 13 problemowych na podstawie dzieł: św. Augustyna $(7)^{11}$, św. Ambrożego (3) ${ }^{12}$, Klemensa Aleksandryjskiego $(1)^{13}$, Orygenesa $(1)^{14}$, Wenancjusza Fortunata $(1)^{15}$ oraz 13 tłumaczeniowych z pism: św. Augustyna $(11)^{16}$, św. Ambrożego (1) ${ }^{17}$ oraz Rufina z Akwilei $(1)^{18} \mathrm{z}$ dołączonym wstępem i komentarzem.

${ }^{10}$ Por. Ewa Nowak, Gelasius. Adversus Andromachum contra lupercalia, 1989; ks. Józef Targosz, Ildephonsus Toletanus, De virginitate perpetua sanctae Mariae confessio, 1991; ks. Jerzy Olszowski, Św. Ambroży, De apologia prophetae David, 1991; O. Arkadiusz Natalis Walkowiak, Św. Ambroży, Exhortatio virginitatis, 1999; Monika Banaś, Św. Ambroży, De virginitate, 1999; ks. Przemysław Jędrzejewski, Św. Ambroży, De Helia et ieiunio, 1999; Monika Kiernozek, Św. Ambroży, De interpellatione Job et David, 1999; ks. Krzysztof Burczak, Zbiór 38 homilii „Chrysostomus Latinus” (Nr 6, 8, 27, 32 i 33), 1997.

${ }^{11}$ Por. Ks. Wojciech Chuchała, Znaczenie "Eneidy" Wergiliusza w „De civitate Dei" św. Augustyna, 1990; ks. Ignacy Pająk, Obraz pogańskiego społeczeństwa rzymskiego w „De civitate Dei" św. Augustyna, 1991; Elżbieta Meger, Actio i contemplatio w dialogach filozoficznych św. Augustyna; Urszula Stojańska, Obraz bóstw ziemskich w „De civitate Dei” św. Augustyna, 1993; Lidia Gorycka, Obraz dziecka w „Confessiones” i dialogach filozoficznych św. Augustyna, 1993; Elżbieta Nazaruk, Dziewictwo, matzeństwo, rodzina w ,Enarrationes in Psalmos” św. Augustyna, 1995; Joanna Kozińska, Motyw „drogi” w „Enarrationes in Psalmos” św. Augustyna, 1997.

12 Por. Ks. Adam Filipowicz, Motyw „śmierci” w „Orationes funebres” św. Ambrożego, 1998; ks. Jerzy Jurkiewicz, Motyw „pokory” w Expositio Evangelii secundum Lucam” św. Ambrożego, 1998; Katarzyna Słonimska, Motyw „matki” w „Expositio Evangelii secundum Lucam” św. Ambrożego, 1998.

${ }^{13}$ Por. Ks. Norbert Widok, Eklektyzm filozofii w pismach Klemensa Aleksandryjskiego, 1991.

${ }^{14}$ Por. Ks. Mariusz Szram, Alegorie mądrości Bożej w pismach Orygenesa, 1996.

15 Por. Ks. Wenancjusz Żmuda, Mysterium crucis w hymnach Wenancjusza Fortunata, 1999.

${ }^{16}$ Por. Ks. Zbigniew Wróbel, Św. Augustyn, De patientia, 1992; ks. Wladysław Bienias, $\hat{S}$ w. Augustyn, De fide et symbolo, 1994; ks. Tadeusz Gacia, Św. Augustyn, De bono viduitatis, 1995; O. Krzysztof Kościelniak, Św. Augustyn, De nuptiis et concupiscentia liber primus, 1995; O. Jerzy Damian, Św. Augustyn, De coniugiis adulterinis liber primus, 1996; ks. Marek Cieśluk, Św. Augustyn, De coniugiis adulterinis liber secundus, 1996; Monika Majcher, Św. Augustyn, Epistola 185: De correctione donatistarum liber, 1999; Magdalena Ziętal, Sw. Augustyn, Epistola 187: De praesentia Dei liber, 1999; Renata Bobel, Św. Augustyn, De sancta virginitate (1-30), 1999; Honorata Bojko, Św. Augustyn, De sancta virginitate (31-57). 
Dysertacje doktorskie z literatury wczesnochrześcijańskiej obronili: Marian Babiński - Argumentacja retoryczna $w$ pismach apolegetycznych Tertuliana (1994, promotor ks. prof. H. Wójtowicz), ks. Ignacy Pająk - Społeczności w „De civitate Dei” św. Augustyna (1998, promotor ks. prof. A. Eckmann), ks. Tadeusz Gacia - Motyw męczeństwa w twórczości św. Ambrożego (1998, promotor ks. prof. A. Eckmann), ks. Marek Kozera - Páthos i apátheia $w$ Gerontikonie (1998, promotor ks. prof. R. Popowski, kierownik Katedry Języka i Literatury Greckiej Późnego Antyku).

Kolokwium habilitacyjne ks. dra Stanisława Longosza (drugie w dziejach Sekcji Filologii Klasycznej KUL) odbyło się 24 lutego 1999 roku na podstawie całokształtu dorobku naukowego (254 publikacje), z którego został wyłączony monotematyczny cykl trzynastu artykułów na temat: Dramat $i$ teatr starożytny w ocenie pisarzy wczesnochrześcijańskich.

W okresie ostatniego dziesięciolecia wykłady monograficzne z literatury wczesnochrześcijańskiej dla studentów III-V roku Sekcji Filologii Klasycznej prowadzili: ks. Henryk Wójtowicz i ks. Augustyn Eckmann.

Ks. prof. H. Wójtowicz omawiał: Środki stylistyczne w „Paschale carmen” Seduliusza (w roku akad. 1997/98), Życie i twórczość oraz język i styl Seduliusza (1998/99), Lektura i analiza wybranych tekstów Seduliusza (1999/2000). We wrześniu 1998 roku zostało oddane do druku w Towarzystwie Naukowym KUL opracowanie: Sedulius Caelius, Opera omnia. Dzieła wszystkie. Tekst łacińsko-polski. Przełożył, wstępem komentarzem i indeksami opatrzył ks. Henryk Wójtowicz (531 mps); ukazało się drukiem w końcu 1999 roku (ss. 451).

Tematami wykładów monograficznych ks. prof. A. Eckmanna były: Najstarsze pisma chrześcijańskie (1993/94), Rodzina w starożytności chrześcijańskiej (1994/95), Rola pisarzy wczesnochrześcijańskich w tworzeniu kultury europejskiej (1995/96), Ojcowie Kościoła wobec kultury klasycznej (1996/97). Ostatnio ukazała się w druku książka ks. prof. A. Eckmanna: Symbol apostolski w pismach świętego Augustyna, Lublin 1999 (TN KUL, ss. 253+nlb. 3).

Ponadto ks. H. Wójtowicz i ks. A. Eckmann wygłaszali odczyty na temat różnych problemów literatury wczesnochrześcijańskiej na sympozjach naukowych, organizowanych przez Sekcję Filologiczną i Sekcję Patrystyczną przy Komisji Episkopatu ds. Nauki Katolickiej oraz przez Polskie Towarzystwo Filologiczne. Odczyty te albo już zostały opublikowane ${ }^{19}$, albo ukażą się wkrótce drukiem.

17 Por. Anna Smętek, Św. Ambroży, De viduis, 1998.

${ }^{18}$ Por. Ks. Zbigniew Wójtowicz, Rufinus Tyrannius, Expositio Symboli, 1995.

19 Por. np. Ks. H. Wójtowicz, Elegia Seduliusza, w: Elegia poprzez wieki. Konferencja naukowa 8-9 XI 1994, red. I. Lewandowski, Poznań 1995, 101-114; tenże, Inwektywa seduliańska, w: Studia nad kulturą antyczna, red. J. Rostropowicz, Opole, 1997, 131-139; tenże, Katecheza w poezji Seduliusza, w: Orbis antiquus. Studia filologiczne i patrystyczne, red. N. Widok, Opole 1998, 29-38; 
Należy tu jeszcze dodać, że również mgr Ewa Osek, asystentka z Katedry Języka i Literatury Greckiej Późnego Antyku wygłosiła w ostatnich latach poza Lublinem kilka odczytów opartych na literaturze wczesnochrześcijańskiej: w grudniu 1996 roku w Instytucie Filologii Klasycznej Uniwersytetu Wrocławskiego na temat: Przyroda w korespondencji Bazylego Wielkiego i Grzegorza z Nazjanzu ${ }^{20}$; we wrześniu 1998 r. podczas 94 walnego zebrania PTF-u w Łodzi - Krytyka kosmologii Arystotelesa w „Heksameronie” Bazylego Wielkiego ${ }^{21}$; we wrześniu 1999 r. w Kazimierzu Biskupim podczas dorocznego spotkania Sekcji Filologicznej przy Komisji Episkopatu d/s Nauki Katolickiej - Wypowiedzi św. Ambrożego przeciwko dewastacji ziemi ${ }^{22}$; w grudniu 1999 r. w Poznaniu podczas zorganizowanej przez Instytut Filologii Klasycznej UAM ogólnopolskiej interdyscyplinarnej sesji nt. „Łacińska proza naukowa” - Nazwy zwierząt morskich w „Heksameronie” św. Ambrożego 23 .

Wymienione tu osoby w różnym stopniu zasłużyli się przez swoje studia i odczyty w propagowaniu literatury wczesnochrześcijańskiej.

Największe jednak znaczenie w badaniach nad antykiem chrześcijańskim ma niewątpliwie prof. dr hab. Leokadia Małunowiczówna, która została docentem na podstawie pracy: De voce sacramenti apud Hilarium Pictaviensem, Lublin 1956. Ona też jako pierwsza, początkowo bez akceptacji innych, od roku 1958 kierowała na Filologii Klasycznej pracami magisterskimi z literatury wczesnochrześcijańskiej. Zasługą jej było również utworzenie w roku 1969 za rektoratu ks. prof. dra hab. Wincentego Granata Międzywydziałowego Zakładu Badań nad Antykiem Chrześcijańskim, którego została zastępcą kierownika. Kierownictwo Zakładu objął natomiast Jan Maria Szymusiak SJ. Miałem szczęście brać udział w tym założycielskim zebraniu powołującym do działalności Zakład Antyku Chrześcijańskiego.

W naszym Uniwersytecie z Niej jesteśmy wszyscy jako cultores antiquitatis christianae. Vivant sequentes!

tenże, Seduliańska sztuka imitacji Wergiliusza, tamże 39-44; tenże, Grzech pierworodny w twórczości Seduliusza, VoxP 17(1997) z. 32-33, 277-289.

${ }^{20}$ Druk przewidziany w „Classica Wratislaviensia”.

21 Odczyt wygłoszony 26 IX 1998 roku w Łodzi na XCIV Walnym Zgromadzeniu PTF ukazał się drukiem w Collectanea Philologica Deodato Wiśniewski oblata, III, Łódź 1999, 161-172.

22 Por. VoxP 18(1998) z. 34-35, 183-194; w tymże tomie (ss. 389-413) autorka publikuje artykuł: Wizja prapoczq̨tów świata w „Heksameronie” św. Bazylego część I, a w tym tomie część II.

${ }^{23}$ Druk przewidziany w aktach konferencji. 


\section{DE MERITIS PHILOLOGIAE CLASSICAE IN CATHOLICA UNIVERSITATE LUBLINENSI IN LITTERIS CHRISTIANIS ANTIQUIS PROPAGANDIS}

\section{(Argumentum)}

Relatio haec actionem philologiae Classicae ab MCMLVIII usque ad MCMXCIX annum attinet. Leocadia Małunowicz, quae anno MCMLI ex universitate Copernicana ab communistis eiecta in Catholicam Universitatem Lublinensem venit, prior inter omnes XXIV quaestiones patristicas elaborandas litterarum studiosis dabat. Quam postea alii quoque docentes et professores Sectionis Philologiae Classicae sequebantur. Hoc modo studiosi LXXXII dissertatiunculas ad gradum magistri et quattuor dissertationes ad gradum doctoris scripserunt. Inter moderatores harum dissertationum fuerunt: Janina Pliszczyńska-Niemirska (V opera a studiosis scripta), Henricus Podbielski (III), Remigius Popowski (III), Marianus Nagnajewicz (I), Michael Kaczmarkowski (II), Henricus Wójtowicz (XIX), Augustinus Eckmann (XXVIII).

Quarti anni studiosi in secundo semestri per duas horas in hebdomada praelectionem de christianis litteris Graecis et Latinis auddiebant. In seminariis Latinis nonnumquam textus patristici a studiosis cum Henrico Wójtowicz et Augustino Eckmann legebantur. Variae ac diversae quaestiones patristicae in aspectu philologo saepe in praelectionibus monographicis studiosis destinatae exponebantur, exempli causa apud Leocadiam Małunowicz (IV quaestiones), Henricum Wójtowicz (VII), Augustinum Eckmann (IX). Henricus Wójtowicz et Augustinus Eckmann praelectiones de variis ac diversis quaestionibus litterarum christianitatis antiquae in symposiis Sectionis Philologae ac Sectionis Patristicae in Commissione Doctrinae Catholicae Episcoporum Polonorum saepe habebant. Etiam Eva Osek IV quaestiones de litteris antiquitatis christianae extra Lublinum esposuit. Senatus Academicus Catholicae Universitatis Lublinensis Cathedram Litterarum Antiquitatis Christianae anno MCMXCIV condidit et Augustinum Eckmann moderatorem eius fecit. Gradum habilitationis academicae in Sectione Philologiae Classicae anno MCMXCIX dr Stanislaus Longosz accepit.

Meritum maximum Leocadiae Małunowicz fundatio Instituti Antiquitatis Christianae Catholicae Universitatis Lublinensis anno MCMLXIX fuit, cuius moderator hoc tempore Stanislaus Longosz est. 